\title{
SpyGlass DS-guided conversion of transmural pancreaticogastrostomy drainage to transpapillary drainage by rendezvous via a lumen-apposing metal stent
}

Recently, we reported a successful endoscopic ultrasound-guided pancreatic duct (PD) drainage using a lumen-apposing metal stent (LAMS) plus a pigtail stent in a 44-year-old man with chronic pancreatitis and PD stricture [1]. The patient's course was satisfactory and 5 months later conversion of the transmural drainage to transpapillary drainage was planned.

The mature fistula, derived from the pancreaticogastrostomy using the LAMS, was used as a port to facilitate access of a SpyScope (Boston Scientific, Natick, Massachusetts, USA) through a therapeutic upper scope. First, a "buried stent effect" was found in the stomach ( $\triangleright$ Fig. 1). The LAMS was unearthed using grasping forceps. Then the cholangiopancreatoscope was positioned at the inner end of the stent, and a 0.035 -inch guidewire was advanced in an antegrade direction towards the papilla ( $\mathbf{F i g . 2}$ and $\triangleright$ Fig. 3 ). Contrast filling using an endoscopic retrograde cholangiopancreatography cannula revealed a severe PD stricture, and allowed advancement of the guidewire to inside the duodenal lumen ( $\triangleright$ Fig. 4). Curiously, no contrast filling of the smallbowel lumen was observed, and the antegrade approach was aborted and changed to a rendezvous method. The scope was exchanged for a duodenoscope, and good positioning of the guidewire in the duodenal lumen was confirmed ( $\triangleright$ Fig. 5). This allowed retrograde pancreatic cannulation, and dilation of the stricture in the pancreatic head using a 6-mm biliary balloon. Finally, a double-pigtail plastic stent ( $7 \mathrm{Fr} \times 10 \mathrm{~cm}$; Boston Scientific) was inserted into the major papilla and inside the PD, and its inner end was located in the gastric body, through the LAMS ( Fig.6; Video 1). No adverse events were reported.

There is a lack of knowledge about the behavior of transmural drainage in longterm follow-up [2], but it is known that transpapillary drainage more closely re-

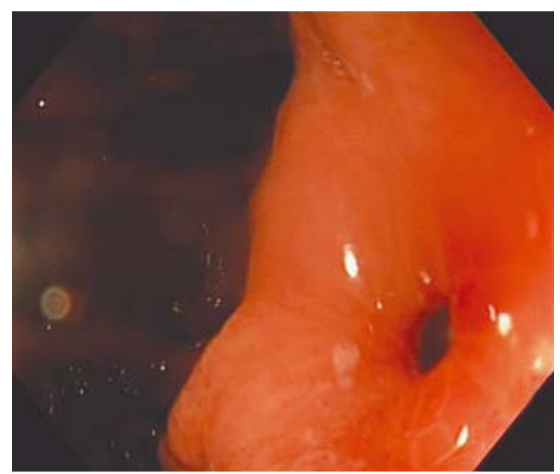

- Fig. 1 SpyGlass DS-guided conversion of transmural drainage to transpapillary drainage in a 44-year-old man with chronic pancreatitis and pancreatic duct stricture. The fistula tract orifice in the gastric body can be seen but the lumenapposing metal stent (AXIOS, $6 \times 8 \mathrm{~mm}$ ) is "buried" by hyperplasia of the gastric mucosa.

plicates normal physiology because pancreatic juice drains directly into the duodenum, an alkaline environment, and enterokinase converts trypsinogen into its active form, trypsin, resulting in the activation of pancreatic digestive enzymes [3].

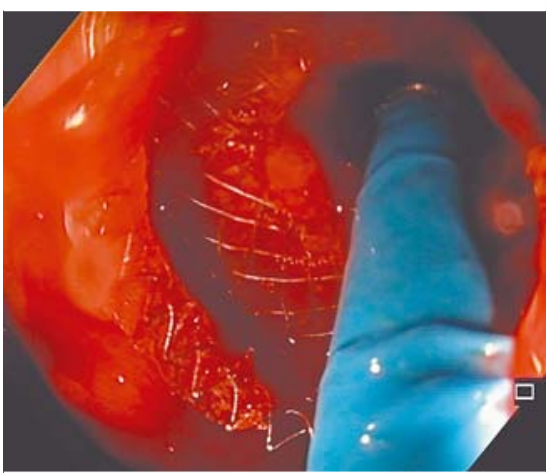

- Fig. 2 Image from a peroral singleoperator cholangiopancreatoscope through a therapeutic upper endoscope. The inner end of the lumen-apposing stent is impacted on the pancreatic duct wall.

Endoscopy_UCTN_Code_TTT_1AR_2AI

Competing interests

None 


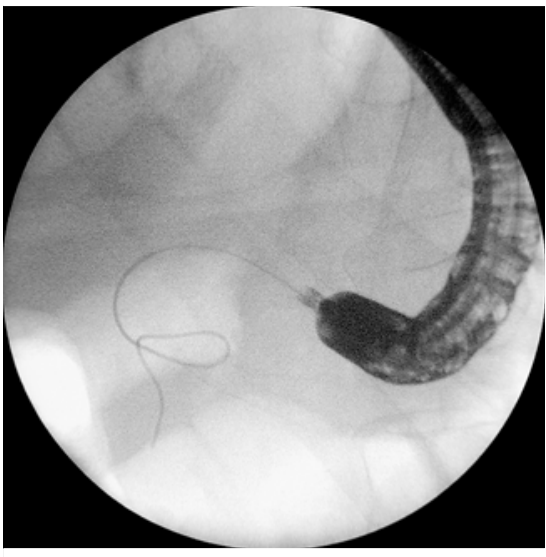

- Fig. 3 SpyGlass DS-guided conversion of transmural pancreatic drainage to transpapillary drainage: a 0.035 -inch guidewire is advanced, through the cholangiopancreatoscope, in an antegrade direction towards the papilla.

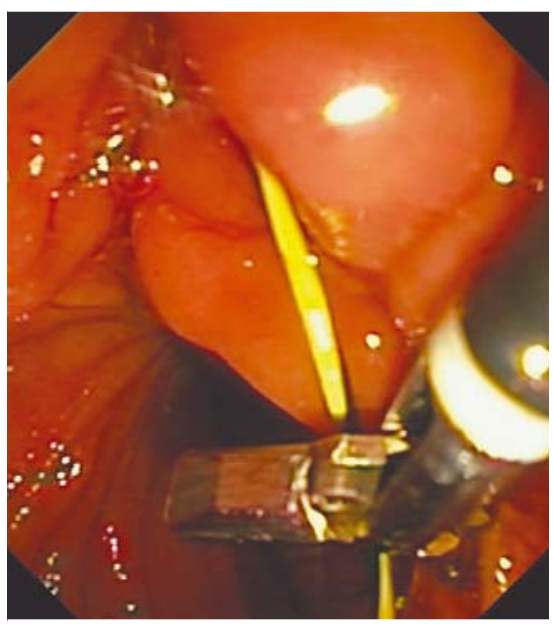

- Fig. 5 After scope exchange: endoscopic view using a duodenoscope. Rendezvous image of the guidewire passing out of the papilla and being grasped by forceps.

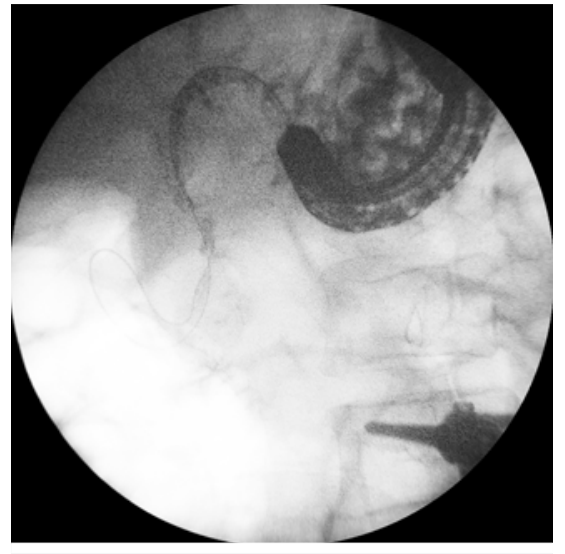

Fig. 4 Fluoroscopic view: an anterograde ductogram. An endoscopic retrograde cholangiopancreatography catheter is inserted through the internal ostomy (pancreaticogastrostomy), and a guidewire is advanced until it reaches the duodenal lumen.

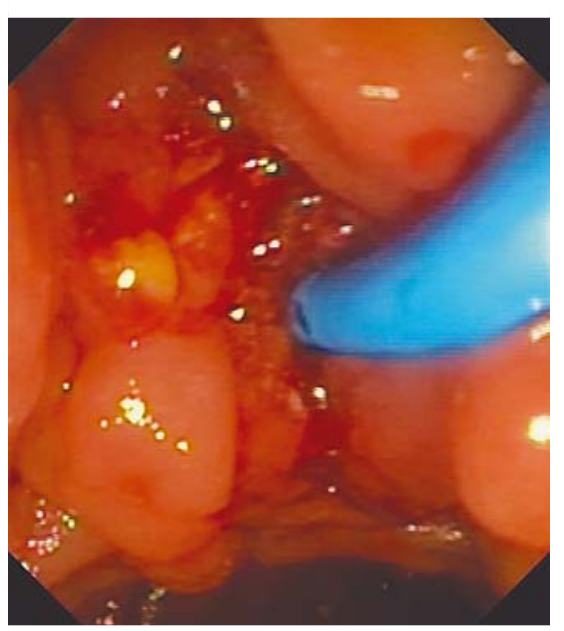

- Fig. 6 Transpapillary double-pigtail plastic stent inserted retrogradely through the pancreatic head stricture.

\section{The Authors}

Joan B. Gornals ${ }^{1}$, Claudia Consiglieri ${ }^{1}$, Susana Redondo ${ }^{2}$

1 Endoscopy Unit, Department of Digestive Diseases, Hospital Universitari de BellvitgeIDIBELL, Barcelona, Catalonia, Spain

2 Department of Anaesthesiology, Hospital Universitari de Bellvitge-IDIBELL Catalonia, Spain

\section{Corresponding author}

\section{Joan B. Gornals, MD, PhD}

Endoscopy Unit, Department of Digestive Diseases, Hospital Universitari de BellvitgeIDIBELL (Bellvitge Biomedical Research Institute), Feixa Llarga s/n, 08907

L'Hospitalet de Llobregat, Barcelona, Catalonia, Spain Fax: +34-93-2607681

jgornals@bellvitgehospital.cat

\section{References}

[1] Gornals JB, Consiglieri C, Vida F et al. Endoscopic ultrasound-guided pancreaticogastrostomy using a lumen-apposing metal stent plus a double-pigtail plastic stent. Endoscopy 2016; 48: 276-277

[2] Chapman CG, Waxman I, Siddiqui UD. Endoscopic ultrasound (EUS)-guided pancreatic duct drainage: the basics of when and how to perform EUS-guided pancreatic duct interventions. Clin Endosc 2016; 49: $161-167$

[3] Feldman M, Friedman LS, Sleisenger MH. Gastrointestinal and liver disease. Volume 1. Pathophysiology, diagnosis, management. 10th edn. Philadelphia: Saunders-Elsevier; 2016

\section{Bibliography}

DOI http://dx.doi.org/10.1055/s-0043-100216 Endoscopy 2017; 49: E97-E98

(c) Georg Thieme Verlag KG

Stuttgart · New York

ISSN 0013-726X 